\title{
On the resulting concrete structure corrosion mechanism and protective measures
}

\author{
Weilin Huang ${ }^{1, a}$, Jinru $Y u^{1, b}$, Yibing Xie ${ }^{1, c}$, Yujie $\mathrm{Ge}^{1, \mathrm{~d}}$ \\ ${ }^{1}$ Qingdao Vocational and Technical College of Hotel Management, China \\ ahwl198808@163.com, biamyujinru88@163.com, cxieyibing525@163.com, 'geyujie870313@163.c \\ om,
}

Keywords: Concrete Structures, Corrosion, Protective measures

\begin{abstract}
As people more and more high to the requirement of construction quality, problems of construction engineering quality get more and more attention. Influencing factors on the quality of the construction project is varied, and omnipresent. Corrosion is the most important influencing factors of concrete structure durability and reliability, in order to guarantee the quality of anti-corrosion engineering, correct selection of anti-corrosion material and construction be based on the nature and function of corrosive medium conditions, the importance of the combination with the engineering site in the design; In this paper, the analysis of concrete structures for different corrosion mechanism and introduces measures to prevent the corrosion of concrete structures from different aspects .
\end{abstract}

\section{Introduction}

Infrastructure is the country's economy, the sustainable development, even is a country sign of social development and people's living standard. The world is paid close attention of the infrastructure durability. Huge economic loss and trouble which is brought of not durable and infrastructure are often neglected by people. Therefore, should not only emphasize the importance of the construction of infrastructure, but also stress the importance of keep its safe and durable for a long time. Our goals and desires is "plan" in one hundred, however, the lack of understanding of "durability", discipline, the specification is not perfect and relative lag, the management maintenance is not in place, especially the existence of the "short-term behavior" and the prevailing adverse factors, Make "durability" of our country's infrastructure problems, faced with more severe situation ${ }^{[1]}$.

At present, the main structure of the world's infrastructure is still reinforced concrete structure, and corrosion is the dominant factors affecting the durability. In the influencing factors of concrete durability, in addition to the freeze-thaw damage, corrosion can be attributed to other factors. In 2001, professor Mehta again with the name " the durability of structures in the 21st century ", was published the following important point: "the infrastructure environment destruction, in many parts of the world, will be serious, a lot of problems, and is an economic problem, corrosion is the main mechanism of the reinforced concrete structure damage." ${ }^{[2]}$ Therefore, the problems of corrosion and protection in concrete is more and more attention, and now has become a research hotspot in the field of the concrete.

\section{Different mechanisms of corrosion of concrete structures}

Plain concrete structure. The basic components of plain concrete is cement, sand, stone and water. The main factor affecting the durability of plain concrete structures is alkali - aggregate reaction ( excessive alkali content in concrete, when exposed to water or humid environments, where the reaction between alkali and alkali reactive aggregate, causing swelling) .

Reinforced concrete structure. Reinforced concrete structure is a complex of concrete and steel, the corrosion morphology can be divided into two types: one is from the lack of durability of concrete, which itself is destroyed, but also due to the bare steel , corrosion and lead to the destruction of the entire structure; second is the concrete itself is not corrosion, but due to the 
external medium role, leading to changes in the concrete itself can stimulate the reinforcement corrosion or ionic chemical properties are introduced, so that the loss of passivation of the steel surface, causing corrosion of steel . From the point of chemical composition, corrosion of reinforcement products $\mathrm{Fe}(\mathrm{OH}) 3, \mathrm{Fe}(\mathrm{OH})$ 2, $\mathrm{FeO} \cdot \mathrm{H} 2 \mathrm{O}$ and $\mathrm{FeO}$, etc., its volume increased 2 to 4 times the volume than the original metal. Due to rust expansion of concrete cover an enormous radiation, its value up to $30 \mathrm{MPa}$ ( ultimate tensile strength greater than concrete ) so along corroded reinforced concrete protective layer cracks (known as longitudinal cracks ). These cracks penetrate further into the corrosive medium steel channel , prompting accelerated corrosion of steel [3] Along cracks in the corrosion rate of steel is often faster than the bare case , until the surface cracks in concrete conduct to a certain extent , the concrete has begun to peel off the protective layer , and finally to the loss of carrying capacity of members .

Prestressed concrete structure. Due to high strength steel and steel under the condition of high stress, corrosion of prestressed concrete structures except with ordinary concrete structure corrosion types may also stress corrosion and hydrogen embrittlement of steel.

Stress corrosion. Stress corrosion is reinforced brittle fracture under tensile stress and corrosive media role in the formation of joint ${ }^{[4]}$. This damage is different from purely mechanical stress damage, can under the effect of low tensile stress, This kind of damage and simple electrochemical corrosion damage also is different, it can happen in the case of corrosive medium is very weak. Corrosive medium and the reinforcement effect, dispersion in the steel surface to form a size distribution of corrosion pits, each pit corrosion equivalent of a gap, and steel under the action of tensile stress, the formation of uneven distribution of stress and stress concentration, at the edge of the gap, when the average stress is not high, the concentration of stress can reach the fracture stress level, and cause of reinforcement fracture. Due to the gap, forming a triaxial tensile stress state is not equal to impede the conduct of reinforced plastic deformation , so that reinforced plastic deformation before breaking performance cannot fully play out, elongation, cold bending and other plastic index decreased significantly. Prestressing steel tensile stress corrosion is the result of joint action with the corrosive medium , the corrosion of reinforced fracture factors play a major role in the initial formation, while the tensile stress is to promote the development of corrosion .

Hydrogen embrittlement. Hydrogen embrittlement is another type of prestressing steel brittle fracture occurs in acidic and slightly alkaline medium. Hydrogen embrittlement and stress corrosion mechanism is completely different . Stress corrosion in the steel of the anode and the cathode region of hydrogen embrittlement occurs due to hydrogen embrittlement of steel reinforcement absorbs hydrogen atom, so that it becomes brittle, so called hydrogen embrittlement . During the corrosion process , the surface of the Steel may be a small amount of hydrogen gas produced , under normal circumstances, the generated atomic hydrogen to form molecular hydrogen quickly, that is harmless at room temperature, but when the process is hindered, a hydrogen atom will be diffusion of the internal reinforcement being absorbed into the metal lattice to the inside, if the internal reinforcement has defects, a hydrogen atom is likely to re- combined into hydrogen molecules . The formation of molecular hydrogen produced a lot of pressure, "bubble". The reinforced brittle. Hydrogen embrittlement of steel when subjected to tensile force exceeds a critical value , it will fracture. Hydrogen sulfide is one of prestressing steel can cause embrittlement of the media.

Fiber reinforced concrete structure. Corrosion mechanism of fiber reinforced concrete and ordinary concrete is basically the same ( As the pressure increases, along microcracks coarse aggregate mortar section and the gradual extension and expansion of the interior, resulting in the accumulation of damage mortar ; crack through , the continuity of the concrete destroyed, gradually lost its carrying capacity, the real damage is gradually becoming a discontinuous process material from a continuous material . ), but the smaller diameter of the fibers , and the uniform distribution , the relative durability of ordinary concrete is better.

\section{Protection measures of concrete structures}

There are many kinds of Measures to prevent corrosion of the concrete, which can basically be divided into two categories: basic protective measures and additional protective measures. 
Basic protective measures. Basic protective measures is based on the consideration of the concrete itself, the corrosion of concrete curb fundamentally. Its protective measures can be divided into:1) Selection and detailed structure of concrete.2) Reasonable selection of materials. Choose the correct type of cement; The thickness of the concrete used in the aggregate, should ensure a dense, while controlling water absorption, and other impurity content of materials, to ensure that the material conditions; concrete mixing and curing water, should consider its impact on the strength of concrete, etc.3) Improve the compactness of concrete. This is the most fundamental way of concrete to prevent corrosion. This method is primarily by slowing the rate of diffusion of Cl- time, to extend the reach of internal concrete Cl- , typically by fly ash , slag and other materials to reduce water-cement ratio to achieve.4) Appropriate increase protective layer thickness. Cl- diffusion delay time to go blunt steel surface, which requires the designer to properly adjust the thickness of the protective layer of concrete depending on the environment, the thickness of the protective layer design should be thickened in corrosive environments.

Additional protective measures. Additional protective measures are divided into four categories: Corrosion-resistant steel, Concrete surface coating protection, Cathodic protection, Adding corrosion inhibitor.

Corrosion-resistant steel. To enhance the corrosion resistance of steel, galvanized steel, copper-clad steel, alloy steel, stainless steel and epoxy-coated steel reinforcement and a series of new varieties or gradually protection methods are widely used. With the diversification of corrosion-resistant steel varieties, galvanized steel, copper-clad steel is rarely used because of its high cost, alloy steel get some development in Japan , and the United States, Canada and Europe for stainless steel and epoxy-coated steel more research, especially epoxy-coated steel , get extensive engineering applications.

Concrete surface coating protection. Concrete surface coating includes a polymer modified mortar, permeable coatings and surface coatings, etc. . Polymer modified cement mortar mostly in the form of an emulsion polymer cement mortar insert, greatly improving the density of the mortar layer and adhesion. Permeable coating material is coated on the rear surface of concrete, the concrete can penetrate a certain range, the occurrence of a chemical reaction with the components of the concrete and block the pores, or self- polymerize to form a hydrophobic continuous film which is formed of a special protective layer , and thus of concrete for protection. Surface coatings are often required to have anti-oxidant, anti- ultraviolet and infrared capability, and sometimes anti-wear, anti-impact and chemical resistant moderate erosion there are certain requirements.

Cathodic protection. The role of the principle of cathodic protection is to make steel cathodic polarization, to eliminate the anode reaction, prevent corrosion occurring purpose. Depending on the cathodic polarization, is divided into two kinds of sacrificial anodes and impressed current method.

Adding corrosion inhibitor. Corrosion inhibitor is corrosion in concrete structures. Rust inhibitor adsorbed on the steel surface, the anodic reaction of corrosion galvanic cell, the cathode reaction inhibition produced so as to achieve the purpose of the repair group. Corrosion inhibitor is easy to use, wide range of applications, long shelf life, etc.

\section{Conclusion}

Design life of reinforced concrete structures require longer, more than 50 years in general , and some even require a hundred years, but the actual life is far less than the design requirements, so a huge concrete structure maintenance costs , and to the state and society huge economic losses. Thus, in the actual project should be based on the actual situation, select the appropriate protection methods, to achieve the best protective effect, minimize losses due to corrosion caused by concrete structures .

\section{References}

[1] A.H. Buchanan, “Structural design for fire safety”, John Wiley \& Sons, Chichester, 2002 
[2] P. Mehta, S. Langley. Monolith Foundation: Built to last a"1000 Years". Concrete International. 2000

[3] Philip Nixon, Keith Quillin, and George Somerville. Sustainable concrete construction. Concrete. 2004

[4] P Zhang, FH Wittmann, T Zhao, EH Lehmann. Neutron imaging of water penetration into cracked steel reinforced concrete. Phys B Condens Matter . 2010 